\title{
Performance of Tetranychus urticae and Neoseiulus californicus on strawberry cultivars and assessment of the effect of glandular trichomes
}

\author{
María F. Gugole Ottaviano • Norma E. Sánchez • \\ Martha F. Roggiero $\cdot$ Nancy M. Greco
}

\begin{abstract}
The performance of Tetranychus urticae and its predator Neoseiulus californicus on ten strawberry cultivars was determined in the laboratory. Development time and survival of $T$. urticae from egg to adult were recorded on Albión, Aromas, Camarosa, Diamante, Festival, Kp, Sabrosa, Selva, Sweet Charlie, and Whitney. Fecundity of newly molted and mated females was recorded during the first 10 days of oviposition. Predation rate and fecundity of $N$. californicus were tested on Albión, Aromas, Festival, Kp, Sabrosa, and Whitney. Predator females reared on each cultivar were placed individually in experimental units, and the number of eggs per day was counted during 3 days. Cultivars with high hairiness (Albión, Aromas, and Festival) and cultivars with low hairiness (Sabrosa, Whitney and $\mathrm{Kp})$ were identified, to assess the effect on the performance of both species. Development time, survival from egg to adult, and fecundity of T. urticae differed among cultivars. Festival was classified as moderately resistant, Aromas and $\mathrm{Kp}$ were moderately susceptible, and the others were intermediate. The number of prey consumed per day per female of $N$. californicus differed between cultivars and time. Fecundity of $N$. californicus did not differ among cultivars; however, it did over time. The development time and fecundity of T. urticae did not differ among high and low hairiness cultivars. The glandular hairiness affected neither consumption nor fecundity of $N$. californicus. According to detrimental and propitious effect on T. urticae and
\end{abstract}

Handling Editor: Guy Smagghe.

M. F. Gugole Ottaviano · N. E. Sánchez

M. F. Roggiero · N. M. Greco ( $\square)$

CEPAVE (CCT La Plata, CONICET-UNLP), Calle 2 No. 584,

1900 La Plata, Argentina

e-mail: ngreco@cepave.edu.ar
$N$. californicus performance, respectively, we concluded that Festival and Albión could be used along with this predator in T. urticae management programs.

Keywords Fragaria $\times$ ananassa . Twospotted spider mite Plant resistance $\cdot$ Biological control $\cdot$ Hairiness

\section{Introduction}

Twospotted spider mite, Tetranychus urticae Koch, is highly polyphagous (Rodríguez and Rodríguez 1987; Yano et al. 1998) and exhibits differential performance when feeding on various plant species (Greco et al. 2006; El-Shafei and Gotoh 2010) or cultivars of the same crop (Krips et al. 1998; Agrawal 2000; Greco and Sánchez 2003). Strawberry, Fragaria $\times$ ananassa Duchesne, is a preferred host for T. urticae (Klingen and Westrum 2007) and therefore is a common pest affecting commercial strawberry crops in several countries. Many cultivars with different degrees of susceptibility or resistance to T. urticae and related species have been reported (Giménez Ferrer et al. 1993; Shanks et al. 1995; Wold and Hutchison 2003; El-Shafei and Gotoh 2010).

The resistance or susceptibility of a crop or cultivar to $T$. urticae can be evaluated by studying herbivore performance (Yano et al. 1998; Lourençao et al. 2000; Xu et al. 2011; Khan 2011). Several characteristics of the life history of an herbivore, such as development time, survival, and fecundity of females, are good indicators of the suitability of a plant for its growth (Agrawal 2000; Krips et al. 1998). In cultivars where the herbivore has a shorter development time (and hence a shorter generation time) and a higher fecundity, the potential growth of the population will be greater. According to Sabelis (1985), changes in 
development time of phytophagous mites are more important for the population growth than are changes in the rate of oviposition. Nevertheless, several authors have identified resistant varieties by analyzing the injury produced to leaves and the abundance of individuals in developing varietal improvement and pest management strategies (Giménez Ferrer et al. 1993, 1994; Shanks and Moore 1995; Shanks et al. 1995; Petrova et al. 2000; Wold and Hutchison 2003; Kazak and Kibritçi 2008). Strawberry has numerous cultivars with different degrees of resistance or susceptibility to T. urticae (Lourençao et al. 2000; Uselis et al. 2006). Selva is a traditional cultivar that has been studied extensively in terms of susceptibility to this pest. Other cultivars studied, to a lesser extent, are Camarosa and Sweet Charlie (Giménez Ferrer et al. 1993; Shanks et al. 1995).

In addition, several studies have been conducted to evaluate physical (trichomes, cuticular waxes, domatias, etc.) (Krips et al. 1998; Skorupska 2004; Oku et al. 2006) and chemical characteristics of the plant (Steinite and Ievinsh 2002) to elucidate possible defense mechanisms. Steinite and Ievinsh (2002) studied the activity of oxidative enzymes and ethylene production in strawberry cultivars with different susceptibility to T. urticae, but they could not identify any biochemical mechanism that significantly influenced resistance. Luczynski (1990) found a negative correlation between development time of $T$. urticae and phenol concentration, as well as between oviposition and the amount of simple and glandular trichomes of strawberry leaves. However, Steinite and Ievinsh (2003) found that simple hairiness was very variable characteristic and depending on phenology of the plant and on growth conditions. Some authors (e.g., Torre Figueiredo et al. 2012) report that strawberry simple hairiness would not be a resistance factor to $T$. urticae. Nevertheless, a negative correlation was found between the distance traveled by the twospotted spider mites and the density of glandular trichomes on the strawberry plant (Torre Figueiredo et al. 2012).

The plant-herbivore-natural enemy interactions warrant investigation because such information is essential to the development of an integrated pest control strategy that combines the use of more resistant cultivars with biological control, since these techniques are not always compatible (Krips et al. 1999). The plants usually have positive effects on natural enemies of herbivores, due to the production of volatile chemical attractants or physical characteristics that provide shelter for survival (Boethel and Eikenbary 1986; Price 1986; Gould et al. 1991; Hare 1992; Vet and Dicke 1992; Krips et al. 1999; Gontijo et al. 2010). However, some cultivars could adversely affect colonization, performance, and effectiveness of natural enemies and be disadvantageous to biological control (Bottrell and Barbosa
1998; Greco et al. 1998). For example, the presence of simple or glandular trichomes may alter search behavior of predators. Moreover, it could differentially affect the consumption of prey from different stages.

Several species of predatory mites prefer plants with hairy leaves (Duso 1992; Karban et al. 1995) that provide protection of eggs from predators and maintain humidity level that reduce egg mortality from desiccation (Krips et al. 1999). However, Afzal and Bashir (2007) found that density and length of trichomes adversely affected the performance of predatory mites pertaining of the family Cunaxidae. While the widest range of responses is found between plant species, varieties of the same crop can also differentially affect the natural enemies (Hare 1992; Eigenbrode et al. 1996). Search efficiency and prey consumption of Phytoseiulus persimilis were negatively affected by the most hairy varieties of Gerbera jamesonii (Krips et al. 1999). Cédola et al. (2001) determined that Neoseiulus. californicus was an inefficient control agent of T. urticae on tomato cultivars with a high number of glandular hairs on the leaf.

Although Ahn et al. (2010) found that the consumption of different stages of $T$. urticae by $N$. californicus was not influenced by simple hairs of two cultivars of strawberry, little is known about the effect of glandular trichomes on the performance of this pest and its predator.

Our hypothesis is that $T$. urticae and $N$. californicus have different performance on various strawberry cultivars and that glandular trichome density of the leaf is one factor that affects performance. In this study, we examined the development time from egg to adult, survival and fecundity of T. urticae, and the consumption rate and fecundity of $N$. californicus on different cultivars. We also evaluated the effect of glandular trichome density on the aforementioned traits of pest and predator. The aim was to provide knowledge to select strawberry cultivars to combine with biological control of $T$. urticae by $N$. californicus in an integrated pest management plan.

\section{Materials and methods}

Culture of mites and plants

Tetranychus urticae and N. californicus were collected from commercial strawberry plants, cultivated under plastic tunnels, in horticultural farms in La Plata, Buenos Aires, Argentina $\left(38^{\circ} 52^{\prime} \mathrm{S}, 57^{\circ} 59^{\prime} \mathrm{W}\right)$. Colonies of both species were reared on new and completely expanded trifoliate strawberry leaves under controlled conditions of $25 \pm 4{ }^{\circ} \mathrm{C}, 60-70 \%$ relative humidity and photoperiod of 14:10 (L:D). The petioles were placed in water-filled tubes (height $7 \mathrm{~cm}$, diameter $2 \mathrm{~cm}$ ) to keep the leaves turgid. To 
initiate the T. urticae colony, leaves were infested with newly copulated females using a fine brush. Tubes were placed in plastic containers $(500 \mathrm{ml})$ covered with plastic film. To breed $N$. californicus, eggs, immatures, and adults of $T$. urticae were offered to recently mated females by brushing $T$. urticae-infested leaves with a very soft brush. Weekly, individuals were brushed to new and fresh leaves to maintain the colonies.

Strawberry runner plants came from nurseries in Argentina that imports and produces several cultivars from various countries. Evaluated cultivars were Albión, Aromas, Camarosa, Diamante, Festival, Kp, Sabrosa, Selva, Sweet Charlie, and Whitney. Plants were individually planted in May, in 30-cm plastic pots containing fertile soil mixed with peat, and were grown in a greenhouse under natural light and temperature conditions.

Development time, survival, and fecundity of T. urticae on strawberry cultivars

The experimental unit was a plastic cage $(2.7 \mathrm{~cm}$ diameter) with a floral foam disk ( $2 \mathrm{~mm}$ height) on bottom, then an agar disk (1.8 cm diameter), and finally a strawberry leaf disk, of the same diameter, with the abaxial side upward. The disks within plastic capsules were surrounded by water to prevent individuals from escaping and to maintain moisture in the device. Tetranychus urticae eggs from females fed on each cultivar (treatment) were put individually in the experimental units. To ensure optimal conditions of strawberry disks for mites, they were replaced whenever necessary moving mites with a fine brush.

Development time and the survival of individuals from egg to adult emergence were recorded daily for each experimental unit of each treatment. After four consecutive days of observations, unhatched eggs were considered dead. The number of replicates per cultivar was between 45 and 56. The variation in development time of T. urticae among different cultivars was analyzed using the KruskalWallis nonparametric single factor analysis of variance, because data did not meet the assumptions of the parametric analysis of variance (ANOVA). Subsequently, multiple comparisons were made of the average rank for each pair of groups, calculating the $\mathrm{z}$-average value for each comparison, and their probability (corrected for the number of comparisons) for a two-tailed significance test (Zar 1996). The Kaplan-Meier product-limit survival curve analysis (Kaplan and Meier 1958) was used to examine the influence of cultivar on survival. This analysis considers data from individuals that escaped from the experimental unit and those that were alive at the end of the experiment as censored data. Data from individuals who die during the experiment are categorized as completed. In this study, no individual escaped experimental unit, so only data of those remaining alive at the end of the experiment were considered like censored. Preimaginal survival curves were compared using a multiple comparison chi-square test, and then pairwise comparisons were made by the Gehan-Wilcoxon (Gehan and Thomas 1969).

Fecundity (eggs/female) was recorded during the first 10 days of oviposition period in those recently molted to this stage and mated. The number of replicates per treatment ranged from 6 to 20. The fecundity was analyzed by one-way ANOVA and Tukey's post hoc test.

Cultivars were grouped according to different classes of susceptibility or resistance, based on the analysis of the development time, survival, and fecundity of T. urticae combined. For each characteristic analyzed (development time from egg to adult, preimaginal survival, and fecundity), we identified two groups of cultivars with contrasting levels of it (high and low), according to the following criteria: within a group, the value of the feature was statistically similar in all cultivars, while among the groups, pairwise comparisons were significantly different. Those cultivars that did not meet these criteria were considered intermediate for that feature. It was considered that a shorter development time, higher survival, and fecundity will promote population growth of T. urticae. Development time was categorized as favorable $(\mathrm{F})$ when it was shorter, adverse (A) when it was longer, and intermediate (I) when the value was between $F$ and A. Survival and fertility were considered $\mathrm{F}$ when they were higher, $\mathrm{A}$ when they were lower, and I when values were between $\mathrm{F}$ and $\mathrm{A}$. Cultivars that showed favorable levels for the three characteristics were considered susceptible (S), and those that showed adverse levels for the three characteristics were considered resistant (R). Susceptibility was classified as moderate (MS) for cultivars which had two variables $\mathrm{F}$ and one A or I, as moderate resistance (MR) which had two A characteristics and one F or I. The cultivars were considered intermediate (I) when they presented the three variables I; two I and one F; two I and one A; or one F, one A, and one I.

\section{Predation rate and fecundity of $N$. californicus} on strawberry cultivars

To evaluate the predation rate and fecundity of $N$. californicus on different strawberry cultivars, Albión, Aromas, Festival, Kp, Sabrosa, and Whitney were tested. Strawberry leaves of each cultivar with 20 eggs of $N$. californicus were placed in petri dishes with moistured filter paper on the bottom and fed T. urticae. After 6 or 7 days, matings were observed and mated females were placed individually in the experimental units belonging to each cultivar. The experimental unit was a petri dish $(8 \mathrm{~cm}$ diameter $)$ with a 
strawberry leaf disk ( $4 \mathrm{~cm}$ diameter) placed on an agar disk ( $5 \mathrm{~cm}$ diameter by $3 \mathrm{~mm}$ deep). The disks were surrounded by water to prevent individuals from escaping and to maintain suitable moisture. Each female was fed 5 eggs, 5 immature, and 5 adults of T. urticae. Preys consumed were replaced daily to maintain constant food. The number of prey consumed per day and the number of eggs laid were registered at 24, 48 and $72 \mathrm{~h}$. The number of replicates per treatment ranged from 10 to 20 .

Prey consumption by the predator and fecundity per day in each cultivar were analyzed by repeated measure oneway ANOVA. Previously, Mauchly's Sphericity test was used to test the assumption of circularity. When this assumption could not be met, the adjustment of the $F$ statistic degrees of freedom was performed by the Greenhouse-Geisser method (Scheiner and Gurevitch 2001). Multiple comparisons were made with the Bonferroni test (Zar 1996).

Effect of glandular trichomes on T. urticae and $N$. californicus

Randomly selected mature leaflets were collected, and the multicellular uniseriate glandular capitates trichomes, 0.04-0.05 mm in length (Steinite and Ievinsh 2003), were quantified on the abaxial surface of leaflets of Albión, Aromas, Festival, Camarosa, Kp, Sabrosa, and Whitney cultivars. The leaflets were dipped in $5 \%$ sodium hydroxide during 4 days to eliminate the cellular content and washed in distilled water. Then, they were immersed in sodium hypochlorite (active chlorine $60 \mathrm{~g} / \mathrm{l}$ ) for $8-10 \mathrm{~min}$ or to total clearing and washed with abundant distilled water. Disks (1.8 cm diameter) were cut, placed on slides, and stained with safranin (O'Brien and Mc Cully 1981). The number of glandular trichomes was recorded using an Olympus BX51 stereo microscope (magnification $200 \times$ ) in 7 fields of each disk (from 7 to 12 disks per cultivar), representing $21.88 \mathrm{~mm}^{2}$ and equivalent to $8.6 \%$ of the total disk surface.

The number of trichomes was compared using one-way ANOVA followed by the Tukey's test for multiple comparisons $(P \leq 0.05)$. When data did not meet the assumptions of the ANOVA, a Kruskal-Wallis test was used. From cultivars, two contrasting levels of glandular hairiness (high and low) were identified according to two conditions: a) the difference in the number of trichomes within a group was statistically not significant; b) all pairwise comparisons of number of trichomes between groups were significant.

Development time and fecundity of T. urticae, and predation rate of fecundity of $N$. californicus were compared among cultivars with high and low hairiness by nested ANOVA, where the subordinate classification (cultivars) was nested within the higher level of classification (hairiness). Means were compared by Tukey's test $(P \leq 0.05)$. Nonparametric Kruskal-Wallis test was used when data did not meet the assumptions of the parametric analysis of variance.

\section{Results}

Development time, survival, and fecundity of $T$. urticae on strawberry cultivars

Development time of T. urticae from egg to adult differed among cultivars $\left(H_{(9, N=504)}=64.69 ; P<0.01\right)$ (Fig. 1). On Aromas and Kp, it had lower development time than on Festival, Diamante, Sabrosa, Selva, and Sweet Charlie. On Albión, Camarosa, and Whitney, the development time was intermediate (Table 1).

Preimaginal survival of $T$. urticae was different among cultivars $\left(\mathrm{chi}^{2}=72.22 ; d f=9 ; P<0.001\right)$ (Fig. 2). The cultivars fell into two contrasting groups $(P<0.05)$ : one conformed by Kp and Whitney, and another integrated by Camarosa, Selva, Sabrosa, Sweet Charlie, Festival, and Aromas. In the first group, T. urticae survival was lower than in the second. On Diamante and Albión, survival was intermediate. On Whitney and $\mathrm{Kp}, T$. urticae survival was very low in the egg stage and in the latter cultivar showed another steep decline around day 11 . On the remaining cultivars, survival varied little and it was never below $80 \%$.

The fecundity of $T$. urticae also differed among cultivars $(F=6.31 ; d f=9,115 ; P<0.001)$ (Fig. 3). Fecundity on Festival and Aromas had the lowest values and these cultivars formed a contrasting group with another integrated by Albión and $\mathrm{Kp}$ with the highest fecundity of $T$. urticae. On Camarosa, Diamante, Sabrosa, Selva, Sweet Charlie, and Whitney, fecundity of $T$. urticae was intermediate.

Taking into account the categorization (favorable, adverse, or intermediate) of $T$. urticae characteristics

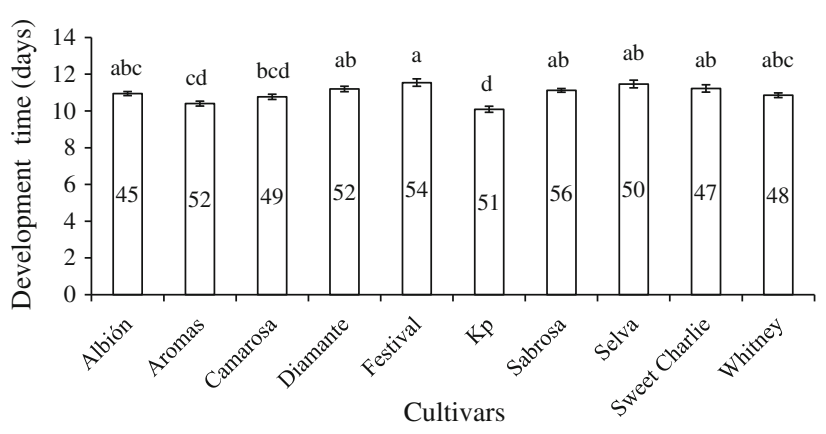

Fig. 1 Development time (mean $\pm \mathrm{SE}$ ) of $T$. urticae from egg to adult on different strawberry cultivars. Bars topped with the same letters were not significantly different $(P>0.05)$. Numbers inside bars indicate the number of replicates 
Table 1 Strawberry cultivar classification according to development time, survival, and fecundity of $T$. urticae, categorized as favorable (F), adverse (A), or intermediate (I) for the population growth

\begin{tabular}{lllll}
\hline Cultivars & $\begin{array}{l}\text { Development } \\
\text { time }\end{array}$ & $\begin{array}{l}\text { Preimaginal } \\
\text { survival }\end{array}$ & Fecundity & Classification \\
\hline Albión & I & I & F & (I) \\
Aromas & F & F & A & (MS) \\
Camarosa & I & F & I & (I) \\
Diamante & A & I & I & (I) \\
Festival & A & F & A & (MR) \\
Kp & F & A & F & (MS) \\
Sabrosa & A & F & I & (I) \\
Selva & A & F & I & (I) \\
Sweet & A & F & I & (I) \\
Charlie & & & & \\
Whitney & I & A & I & (I) \\
\hline
\end{tabular}

$S$ susceptible, $M S$ moderately susceptible, $I$ intermediate between susceptible and resistant, $M R$ moderately resistant, $R$ resistant

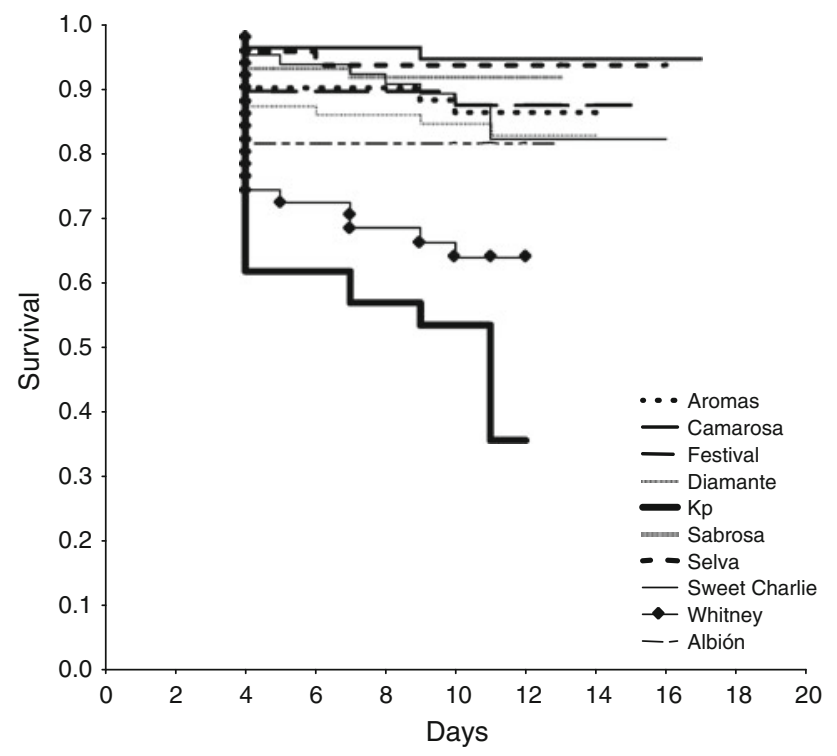

Fig. 2 Preimaginal survival of $T$. urticae on different strawberry cultivars

(development time, preimaginal survival, and fecundity) and their combination, Festival resulted the only cultivar classified as moderately resistant (MR), while Aromas and Kp were moderately susceptible (MS) and the remaining were considered intermediates (I) (Table 1).

Predation rate and fecundity of $N$. californicus on strawberry cultivars

The total number of prey (eggs, nymphs, and adults of T. urticae) consumed per day per adult female of

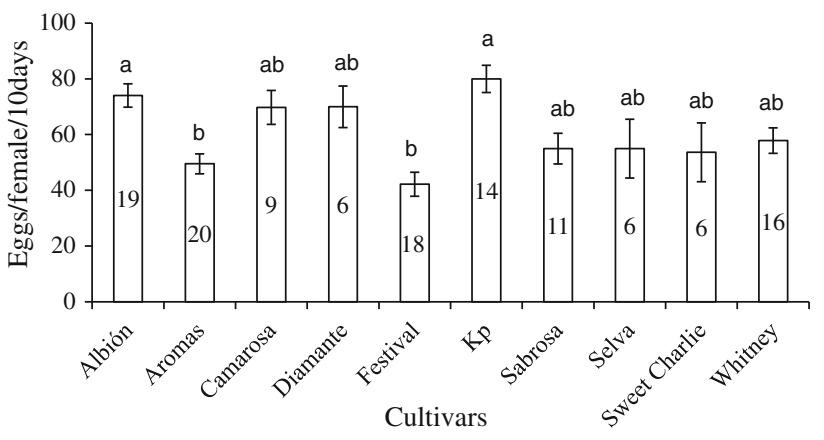

Fig. 3 Fecundity (mean \pm SE) of T. urticae on different strawberry cultivars. Bars topped with the same letters were no significantly different $(P>0.05)$. Numbers inside bars indicate the number of replicates

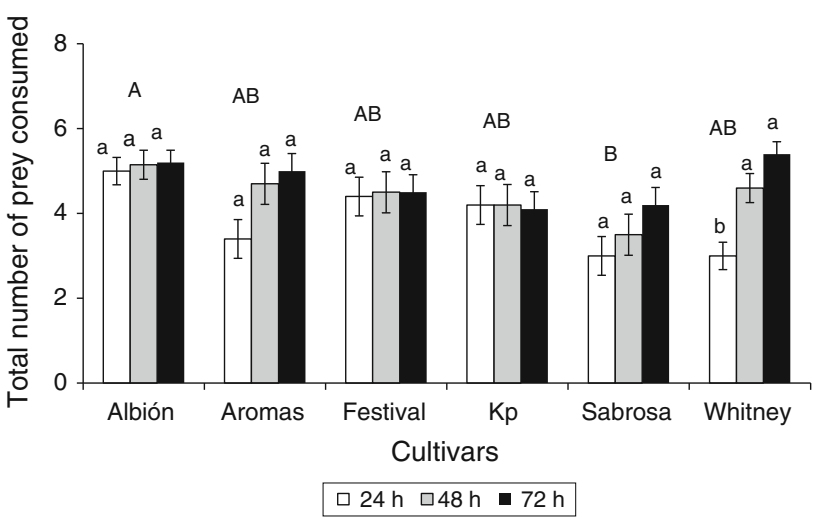

Fig. 4 Mean number ( \pm SE) of prey (eggs, nymphs, and adults of $T$. urticae) consumed per day by adult females of 24-, 48-, and 72-h old of $N$. californicus on different strawberry cultivars. The same capital letters indicate no significant differences between cultivars, and same small letters indicates not significant differences in consumption along the time on each cultivar $(P>0.05)$

N. californicus was different between cultivars and time (cultivar $F=4.73$; $d f 5,72 ; P<0.001$; time $F=7.81$; $d f$ 2, 148; $P<0.001)$, and there was a significant interaction between factors $(F=2.09$; df 10,$148 ; P=0.029)$. The predation rate was higher on Albión than on Sabrosa. An increase in prey consumption was observed over time in Aromas, Sabrosa, and Whitney, but it was significant at 48and 72-h old only in Whitney (Fig. 4).

The fecundity of $N$. californicus did not exhibit differences among cultivars; however, it did over time (cultivar: $F=1.89 ; \quad d f 5,74 ; \quad P=0.106 ;$ time: $F=41.94 ; d f$ adjusted by the Greenhouse-Geisser method 1.81, 134.08; $P$ adjusted $<0.001)$. There was no significant interaction between cultivar and time $(F=0.45$; $d f$ adjusted by the Greenhouse-Geisser method 9.06, 134.08; $P$ adjusted $=$ 0.918 ). The lowest fecundity values were registered in females of 24-h old and the highest at $72 \mathrm{~h}$ (Fig. 5). 
Effect of glandular trichomes on T. urticae and $N$. californicus

The number of glandular trichomes of leaves differed among cultivars $\left(H_{(6, N=66)}=53.56 ; P<0.01\right)$ (Fig. 6). Two contrasting groups were identified: Albión, Aromas, and Festival belonged to the high hairiness group, while Sabrosa, Whitney, and Kp to low hairiness. Camarosa was not included in any group because it had an intermediate hairiness.

The development time of $T$. urticae from egg to adult did not differ among high and low hairiness cultivars $\left(H_{(1, N=285)}=0.513 ; P=0.474\right)$. Fecundity did also not differ between both cultivar groups (hairiness $F=0.53$, $d f=1, \quad P=0.510 ; \quad$ cultivars $\quad F=13.15, \quad d f=4$, $P<0.001 ; d f$ error $=98)$, but differences were found within groups: fecundity of $T$. urticae females was higher on Albión than on Aromas and Festival, all with high hairiness, and on $\mathrm{Kp}$, it was higher than on Sabrosa and Whitney, the three cultivars with low hairiness (Fig. 7).

The prey consumption by $N$. californicus did not vary in relation to the glandular leaf hairiness, but differences were found between cultivars (hairiness $F=3.51 ; d f=1$; $P=0.065 ;$ cultivars $F=5.92 ; d f=4 ; \quad P<0.001 ; d f$ error $=74)$. On Sabrosa, consumption was lower than on Whitney and Albión. Results indicated that in spite that these two latter cultivars belonged to hairiness contrasting groups, consumption of $N$. californicus was similar (Fig. 8).

The effect of glandular hairs on the fecundity of $N$. californicus was not analyzed because this feature did not exhibit significant differences between varieties.

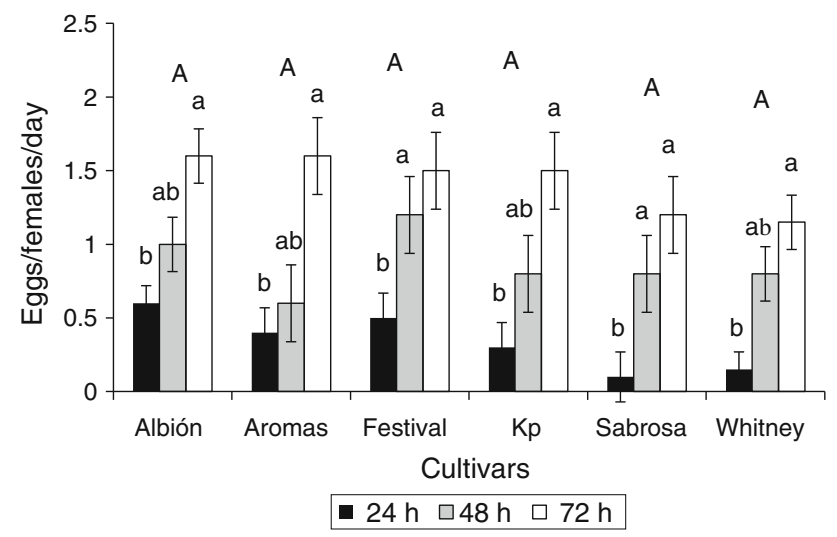

Fig. 5 Fecundity (mean $\pm \mathrm{SE}$ ) of 24-, 48-, and 72-h old $N$. californicus females. The same capital letters indicate no significant differences between cultivars, and same small letters indicates no significant differences in consumption along the time on each cultivar $(P>0.05)$

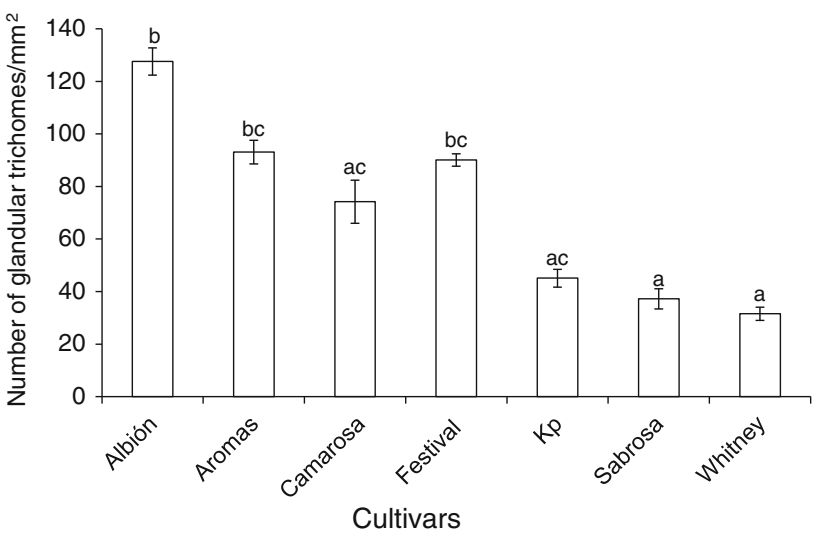

Fig. 6 Mean number $( \pm \mathrm{SE})$ of glandular trichomes per $\mathrm{mm}^{2}$ of leaves from different strawberry cultivars. Bars with the same letter did not significantly differ $(P>0.05)$

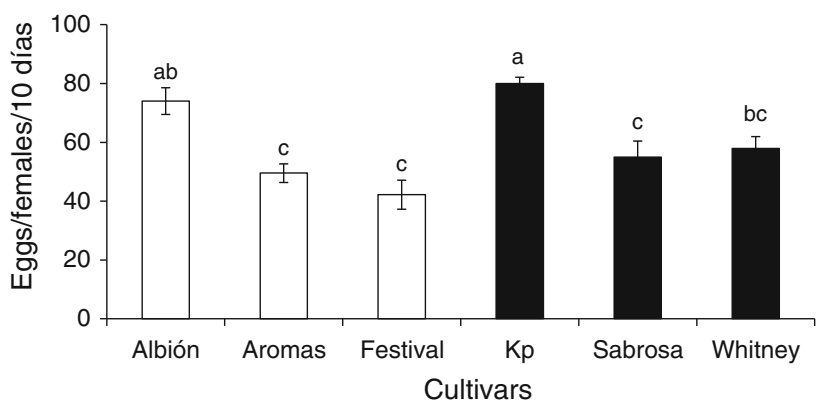

Fig. 7 Fecundity (mean number of eggs/female/10 days \pm SE) of $T$. urticae on strawberry cultivars with high (white columns) and low (black columns) glandular trichomes. Columns with the same letter are not significantly different $(P>0.05)$

\section{Discussion}

Susceptibility and resistance of strawberry cultivars to $T$. urticae have been documented by several authors (Giménez Ferrer et al. 1993; Shanks and Moore 1995; Lourençao et al. 2000; Uselis et al. 2006). In this study, Kp and Aromas were classified as moderately susceptible. Tetranychus urticae had both development time and fecundity favorable to population growth, but preimaginal survival was low, while in Aromas, their development time and preimaginal survival were favorable, but fecundity was low. By contrast, Festival showed moderate resistance since both development time and fecundity were unfavorable for $T$. urticae, but preimaginal survival was high. The other cultivars studied were considered with an intermediate susceptibility or resistance. Kazak and Kibritçi (2008) studied, among other cultivars, Camarosa, Sweet Charlie, and Selva as host of $T$. cinnabarinus Boisduval and found no difference in development time coinciding with the results of the present study for $T$. urticae. Moreover, these authors found differences in the intrinsic growth rate, considering Sweet Charlie a less favorable cultivar to the 


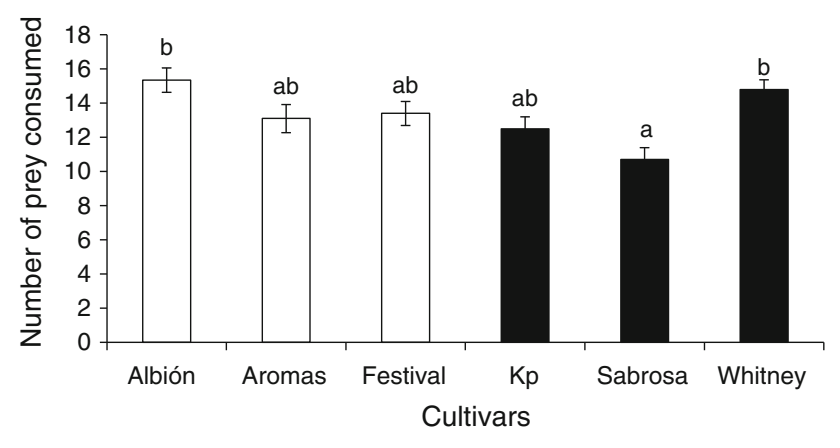

Fig. 8 Consumption (mean \pm ES) of different life stages of $T$. urticae by $N$. californicus females at $72 \mathrm{~h}$, in strawberry cultivars with high (white columns) and low (black columns) glandular trichomes. Columns with the same letter are not significantly different $(P>0.05)$

population growth of T. urticae. According to the evaluated characteristics in the present research, Sweet Charlie like Selva was classified as intermediate between susceptible and resistant. Results obtained for Selva, one of the most widely studied cultivars worldwide, were similar to those reported by other authors (Gimenez-Ferrer 1993; Shanks and Moore 1995; Labanowska, 2007; Kazak and Kibritçi 2008). Moreover, Greco and Sánchez (2003) reported the existence of induced susceptibility by $T$. urticae to their subsequent populations in this cultivar.

The differential performance of T. urticae observed in different cultivars may be due to many physical and chemical plant characteristics. The pubescence is one of the most studied features related to the resistance against arthropods because it provides a defensive barrier against various phytophagous insects and mites (Webster 1975; Levin 1973; Onyambus et al. 2011). However, Harvey and Martin (1980) found a higher density of Eriophyes tulipae Keifer mite in wheat cultivars with dense pubescence. Steinite and Ievinsh (2003) and Torre Figueiredo et al. (2012) observed that the simple hairiness would not be a factor of resistance to T. urticae. Similarly, results of the present study suggest that glandular hairiness would not be an important resistance factor for T. urticae on strawberry, since development time and fecundity of $T$. urticae females did not differ between cultivars with high and low glandular hairiness. Torre Figueiredo et al. (2012) found a negative correlation between the distance traveled by $T$. urticae and density of glandular trichomes on strawberry leaves, suggesting that ambulatory dispersion could be negatively affected by this kind of trichomes.

In this study, $N$. californicus had higher prey consumption in Albión than in Sabrosa. The glandular hairiness did not influence the rate of consumption. Fecundity of this phytoseiid did not differ between cultivars. The functional and numerical response of this predator was adversely affected by the glandular hairs in other crops such as tomato (Cédola et al. 2001). However, the glandular trichomes of tomato leaf are larger than those of the strawberry leaf and have toxic exudates that could hinder the displacement and performance.

Some of the strawberry cultivars tested in this study showed different degrees of resistance or susceptibility to $T$. urticae and affected differentially the rate of consumption of $N$. californicus. However, glandular hairiness of the leaf was not identified as the factor responsible for the differences found. Festival could be included in an IPM because it was classified as moderately resistant to $T$. $u r$ ticae and the consumption rate of $N$. californicus was intermediate on this cultivar. Albión could be another cultivar to be taken into account in an IPM, because it showed intermediate resistance to $T$. urticae, while the predator's consumption rate was relatively high. In summary, according to the results of this study, $N$. californicus exhibited a better performance on Festival and Albión than on the other cultivars; therefore, they could be integrated with the biological control by this predator in pest management programs.

\section{References}

Afzal M, Bashir MH (2007) Influence of certain leaf characters of some summer vegetables with incidence of predatory mites of the family Cunaxidae. Pak J Bot 39(1):205-209

Agrawal AA (2000) Host range evolution: adaptation of mites and trade-offs in fitness on alternate hosts. Ecology 81:500-508

Ahn JJ, Kim KW, Lee JH (2010) Functional response of Neoseiulus californicus (Acari:Phytoseiidae) to Tetranychus urticae (Acari: Tetranychidae) on strawberry leaves. J Appl Entomol 134:98-104

Boethel DJ, Eikenbary RD (eds) (1986) Interactions of plant resistance and parasitoids and predators of insects. Ellis Horwood, Chichester

Bottrell DG, Barbosa P (1998) Manipulating natural enemies by plant selection and modification: a realistic strategy? Ann Rev Entomol 43:347-367

Cédola CV, Sánchez NE, Liljesthröm GG (2001) Effect of tomato leaf hairiness on functional and numerical response of Neoseiulus californicus (Acari:Phytoseiidae). Exp Appl Acarol 25: 819-831

Duso C (1992) Role of Amblyseius aberrans (Oud.), Typhlodromuns pyri Scheuten and Amblyseius andersoni (Chant) (Acari, Phytoseiidae) in vineyards. J Appl Entomol 114:455-462

Eigenbrode SD, Castagnola T, Roux MB, Steljes L (1996) Mobility of three generalist predators is greater on cabbage with glossy leaf wax that on cabbage with a waxy bloom. Entomol Exp Appl 81:335-343

El-Shafei GMA, Gotoh T (2010) Performance of eighteen tetranychid mite species (Acari: Tetranychidae) on borage and strawberry. Appl Entomol Zool 45:579-585

Gehan EA, Thomas DG (1969) The performance of some two sample tests in small samples with and without censoring. Biometrika 56:127-132

Giménez Ferrer RM, Scheerens JC, Erb WA (1993) In vitro screening of 76 strawberry cultivars for twospotted spider mite resistance. HortScience 28:841-844 
Giménez-Ferrer RM, Erb WA, Bishop BL, Scheerens JC (1994) Hostpest relationships between the twospotted spider mite (Acari: Tetranychidae) and strawberry cultivars with differing levels of resistance. J Econ Entomol 87:168-175

Gontijo LM, Margolies DC, Nechols JR, Cloyd RA (2010) Plant architecture, prey distribution and predator release strategy interact to affect foraging efficiency of the predatory mite Phytoseiulus persimilis (Acari:Phytoseiidae) on cucumber. Biol Control 53:36-141

Gould F, Kennedy GG, Johnson MT (1991) Effects of natural enemies on the rate of herbivore adaptation to resistant host plants. Entomol Exp Appl 58:1-14

Greco NM, Sánchez N (2003) Effects of previously damaged strawberry plants on Tetranychus urticae Koch (Acari: Tetranychidae). Acarologia 43(1):59-65

Greco NM, Sarandón SJ, Pereyra PC (1998) Parasitism of Diatraea saccharalis (Lepidoptera: Pyralidae) eggs by Trichogramma exiguum (Hymenoptera: Trichogrammatidae): influence of Zea mays leaf pubescence. Ecología Austral 8:31-35

Greco NM, Pereyra PC, Guillade A (2006) Host-plant acceptance and performance of Tetranychus urticae (Acari, Tetranychidae). J Appl Entomol 130(1):32-36

Hare JD (1992) Effects of plant variation on herbivore-natural enemy interactions. In: Fritz RS, Simms EL (eds) Plant resistance to herbivores and pathogens ecology evolution and genetic. University of Chicago Press, Chicago

Harvey TL, Martin TJ (1980) Effects of wheat pubescence on infestations of wheat curl mite and incidence of wheat streak mosaic. J Econ Entomol 73:225-227

Kaplan EL, Meier P (1958) Nonparametric estimation for incomplete observation. J Am Stat Assoc 53:457-481

Karban R, English-Loeb G, Walker MA, Thaler J (1995) Abundance of phytoseiid mites on Vitis species: effects of leaf hairs, domatia, prey abundance and plant phylogeny. Exp Appl Acarol 19:189-197

Kazak C, Kibritçi C (2008) Population parameters of Tetranychus cinnabarinus Boisduval (Prostigmata: Tetranychidae) on eight strawberry cultivars. Turk J Agric For 32:19-27

Khan SM (2011) Varietal performance and chemical control used as tactics against sucking insect pest of cotton. Sarhad J Agric 27:255-261

Klingen I, Westrum K (2007) The effect of pesticides used in strawberries on the phytophagous mite Tetranychus urticae (Acari: Tetranychidae) and its fungal natural enemy Neozygites floridana (Zygomycetes: Entomophthorales). Biol Control 43:222-230

Krips OE, Witul A, Willems PEL, Dicke M (1998) Intrinsic rate of population increase of the spider mite Tetranychus urticae on the ornamental crop gerbera: intraspecific variation in host plant and herbivore. Entomol Exp Appl 89:159-168

Krips OE, Willems PEL, Dicke M (1999) Compatibility of host plant resistance and biological control of the Two-Spotted spider mite Tetranychus urticae in the ornamental crop gerbera. Biol Control $16: 155-163$

Labanowska BH (2007) Susceptibility of strawberry cultivars to the two-spotted spider (Tetranychus urticae Koch). J Fruit Ornam Plant Res 15:133-146

Levin DA (1973) The role of trichomes in plant defense. Q Rev Biol 48:3-15

Lourençao AL, Moraes GJ, Passos FA, Ambrosano GMB, Lásaro E, Silva VF (2000) Resistência de Morangueiros a Tetranychus urticae Koch (Acari: Tetranychidae). An Soc Entomol Bras 29(2):339-346

Luczynski A, Isman MB, Raworth DA, Chan CK (1990) Chemical and morphological factors of resistance against the twospotted spider mite in beach strawberry. J Econ Entomol 83:564-569
O'Brien TP, Mc Cully ME (1981) The study of plant structure. Principles and selected methods. Termacarphy Pty. Ltd., Melbourne

Oku K, Yano S, Takafuji A (2006) Host plant acceptance by the phytophagous mite Tetranychus kanzawai Kishida is affected by the availability of a refuge on the leaf surface. Ecol Res 21:446-452

Onyambus GK, Maranga RO, Gitonga LM, Knapp M (2011) Host plant resistance among tomato accessions to the spider mite Tetranychus evansi in Kenya. Exp Appl Acarol 54:385-393

Petrova V, Cudare Z, Steinite I, Laugale V (2000) Preliminary studies on resistance of some strawberry cultivars to spider mite Tetranychus urticae. IOBC WPRS Bull 23:119-122

Price PW (1986) Ecological aspects of host plant resistance and biological control: interactions among three trophic levels. In: Boethel DJ, Eikenbary RD (eds) Interactions of plant resistance and parasitoids and predators of insects. Ellis Horwood, Chichester, pp 11-30

Rodríguez JG, Rodríguez LD (1987) Nutritional ecology of phytophagous mites. In: Slansky F, Rodríguez J (eds) Nutritional ecology of insects, mites, spiders and related invertebrates. Wiley, New York, pp 177-208

Sabelis MW (1985) Reproductive strategies. In: Helle W, Sabelis MW (eds) Spider mites. Their biology, natural enemies and control, vol 1A. Elsevier, Amsterdam, pp 265-278

Scheiner SM, Gurevitch J (2001) Design and analysis of ecological experiments. Oxford University Press, Oxford

Shanks CH Jr, Moore PP (1995) Resistance to twospotted spider mite and strawberry aphid in Fragaria chiloensis, F. virginiana, and $F . \times$ ananassa clones. HortScience 30:596-599

Shanks CH Jr, Chandler CK, Show ED, Moore PP (1995) Fragaria resistance to spider mites at three locations in the United States. HortScience 30(5):1068-1069

Skorupska A (2004) Resistance of apple cultivar to two-spotted spider mites, Tetranychus urticae (Acarina: Tetranychidae). Part II. Influence of leaf pubescence of selected apple cultivars on fecundity of two-spotted spider mites. J Plant Prot Res 44:69-74

Steinite I, Ievinsh G (2002) Wound-induced responses in leaves of strawberry cultivars differing in susceptibility to spider mite. J Plant Physiol 159:491-497

Steinite I, Ievinsh G (2003) Possible role of trichomes in resistance of strawberry cultivars against spider mite. Acta Univ Latviensis Ser Biol 662:59-65

Torre Figueiredo AS, Vilela Resende JT, Ferreira Morales RG, Santos Gonçalves AP, Da Silva PR (2012) The role of glandular and non-glandular trichomes in the negative interactions between strawberry cultivars and spider mite. Arthropod-Plant Interact 7:53-58

Uselis N, Valiuskaite A, Raudonis L (2006) Incidence of fungal leaf diseases and phytophagous mites in different strawberry cultivars. Agron Res 4:421-425

Vet LEM, Dicke M (1992) Ecology of infochemical use by natural enemies in a tritrophic context. Annu Rev Entomol 37:141-172

Webster JA (1975). Association of plant hairs and insect resistance. Miscellaneous publication. $\mathrm{N}^{\circ}$ 1297. Agriculture Research Service, US Department of Agriculture

Wold SJ, Hutchison WD (2003) Varietal resistance to Tetranychus urticae Koch (Acari: Tetranychidae) in Minnesota strawberries and control with bifenthrin. J Entomol Sci 38:692-695

Xu J, Lin KK, Liu SS (2011) Performance on different host plants of an alien and an indigenous Bemisia tabaci from China. J Appl Entomol 135(10):771-779

Yano S, Wakabayashi M, Takabayashi J, Takafuji A (1998) Factors determining the host plant range the phytophagous mite, Tetranychus urticae (Acari: Tetranychidae): method for quantifying host plant acceptance. Exp Appl Acarol 22:595-601

Zar HJ (1996) Biostatistical analysis. Prentice-Hall, New Jersey 